JST 8 (2)(2019)
JURNAL SENI TARI
Terakreditasi SINTA 5
http://iournal.unnes.ac.id/siu/index.php/ist

\title{
Nilai Estetis Tari Lawet di Kabupaten Kebumen
}

\section{Kes Nurshanti ${ }^{1}$, Veronica Eny Iryanti ${ }^{2}$}

Jurusan Pendidikan Seni Drama Tari dan Musik, Fakultas Bahasa dan Seni, Universitas Negeri Semarang, Indonesia

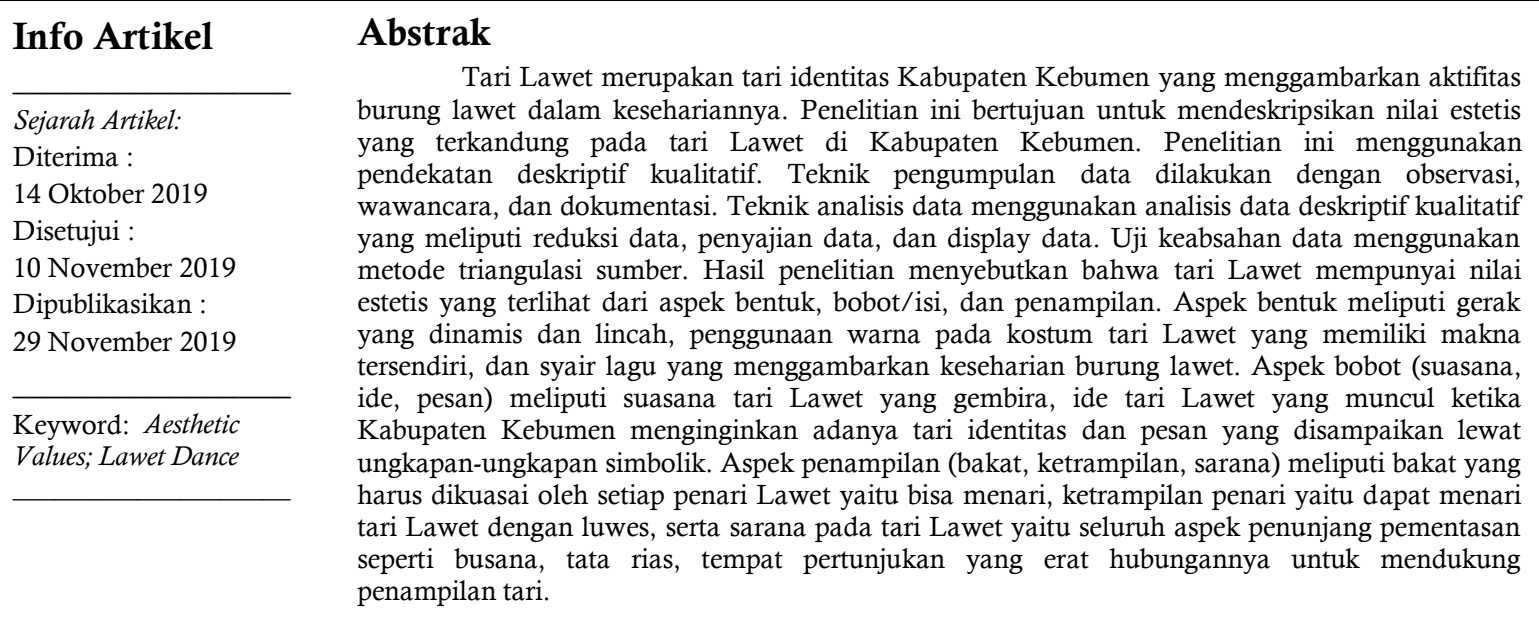

\begin{abstract}
Lawet Lawet dance is a Kebumen regency identity dance that illustrates the activities of lawet birds in their daily lives. This study aims to describe the aesthetic value contained in the Lawet dance in Kebumen Regency. This research use desciptive qualitative approach. Data collection techniques are done by observation, interviews, and documentation. Data analysis techniques using qualitative descriptive data analysis which includes data reduction, data presentation, and data display. Test the validity of the data using the source triangulation method. The results of the study mentioned that the Lawet Dance has aesthetic value that is seen from the aspect of shape, weight / content, and appearance. The aspects of form include dynamic and agile movements, the use of colors in the Lawet dance costume which has its own meaning, and song lyrics that describe the daily life of the lawet. Aspects of weight (atmosphere, ideas, messages) include the happy atmosphere of Lawet dance, Lawet dance ideas that emerge when Kebumen Regency wants identity dances and messages conveyed through symbolic expressions. Appearance aspects (talent, skills, facilities) include talents that must be mastered by every Lawet dancer, that is, able to dance, dancers' skills that can dance lawet with Luwes, and facilities in Lawet dance, namely all aspects of supporting performances such as clothing, make-up, venue which is closely related to supporting dance performances.
\end{abstract}

(C) 2019 Universitas Negeri Semarang

\footnotetext{
Alamat korespondensi:

Gedung B2 Lantai 2 FBS Unnes

Kampus Sekaran, Gunung pati, Semarang, 50229

E-mail: 1. kekesnurshanti@gmail.com

2. veronika@mail.unnes.ac.id
}

ISSN : 2503-2585 


\section{PENDAHULUAN}

Tari sebagai salah satu cabang kesenian merupakan ekspresi manusia yang paling mendasar dan paling tua. Tari adalah suatu bentuk pernyataan imajinatif yang tertuang melalui medium kesatuan simbol-simbol gerak, ruang, dan waktu (Jazuli, 2016: 33).

Kabupaten Kebumen memiliki beragam kesenian tradisional, salah satunya adalah tari Lawet. Tari Lawet Kebumen merupakan karya seni dan kreatifitas dari Bapak Sardjoko yang awal mulanya diciptakan pada Februari 1989. Asul usul tari Lawet adalah keinginan dari Bupati Kebumen pada tahun 1989 untuk diadakan pentas tari masal khas Kebumen dalam rangka untuk pembukaan acara Jambore Daerah Jawa Tengah yang diadakan di Bukit Perkemahan Widoro, Kebumen.

Bapak Sardjoko beserta beberapa seniman lainnya melakukan survei dan pengamatan ke pantai selatan Kebumen, tepatnya di daerah Karang Bolong karena di situlah terdapat goa-goa yang menjadi sarang burung lawet dengan hamparan laut yang luas, burung-burung lawet yang beterbangan di atas samudra, dan beberapa orang yang memanjat goa untuk mengambil / panen sarang burung lawet. Kondisi alam, perilaku satwa serta orang yang mengunduh sarang lawet menjadi inspirasi untuk dituangkan dalam bentuk gerak tarian dan lagu yang berwujud tari Lawet.

Keindahan setiap tari dapat dilihat dari sisi gerak, rias dan busana serta iringan yang digunakan. Melalui aspek-aspek koreografinya, tari Lawet mempunyai nilai keindahan yang dilihat dari segi gerak, rias dan busana serta iringan. Tari Lawet merupakan tari kreasi yang cukup unik sebab ragam gerak tari Lawet berisi tentang kehidupan burung lawet, yaitu menceritakan tentang aktifitas burung lawet dalam kesehariannya, mulai dari bangun tidur, keluar masuk ke goa, terbang, mandi, mencari makan, mengerami telur. Gerakan tari Lawet cenderung lincah dan gembira sesuai dengan karakter burung lawet yang gesit dan lincah.

Selain ragam gerak, yang terlihat menarik dalam sajian tari Lawet adalah penggunaan kostum tari Lawet yang berkarakter seekor burung lawet. Musik dalam tari Lawet menggambarkan suasana syair lagu yang gembira serta mengungkapkan kegiatan burung lawet dari pagi hingga petang. Hal-hal tersebutlah yang menjadikan peneliti tertarik untuk mengetahui, mengungkap dan mendiskripsikan lebih dalam apa sajakah nilai keindahan yang membuat tari Lawet terlihat menarik baik dari keindahan gerak yang dimiliki, iringan maupun busana yang dipakai oleh penari.

Penelitian yang telah dilakukan oleh Erma Lutfyana (2015) yang berjudul Eksistensi Tari Lawet di Kabupaten Kebumen yang menjelaskan tentang eksistensi atau keberadaan tari Lawet. Penelitian tersebut memberikan referensi dan tambahan pengetahuan kepada peneliti mengenai bentuk penyajian tari Lawet.

Penelitian yang berjudul "Nilai Estetis Kesenian Dangsak Di Desa Watulawang Kecamatan Pejagoan Kabupaten Kebumen" dari Jurnal Seni Tari dilakukan oleh Ari Setyawati (2017) yang membahas mengenai nilai estetis kesenian Dangsak. Penelitian tersebut memberikan referensi kepada peneliti mengenai nilai estetis sebuah tarian dilihat dari aspek bentuk, bobot, dan penampilan.

Berdasarkan penelitian terkait, belum ada yang membahas mengenai nilai estetis Tari Lawet di Kabupaten Kebumen, sehingga penelitian ini dapat menambah referensi dan apresiasi tari daerah di Jawa Tengah khususnya Kabupaten Kebumen.

\section{METODE PENELITIAN}

Penelitian yang berjudul Nilai Estetis Tari Lawet di Kabupaten Kebumen menggunakan pendekatan deskriptif kualitatif, pendekatan estetis koreografi, pendekatan etik dan emik. Penelitian ini menggunakan pendekatan deskriptif kulitatif karena peneliti ingin mendiskripsikan keindahan tari Lawet di Kabupaten Kebumen. Data penelitian tentang nilai estetis tari Lawet yaitu berupa data tentang deskripsi gerak tari Lawet. Wujud data dalam penelitian ini 
berupa deskripsi gerak tari Lawet di Kabupaten Kebumen.

Pertama, sumber data primer diperoleh dari penelitian yang dilakukan melalui observasi dan wawancara awal yang dilakukan di Dinas Pendidikan Kabupaten Kebumen yang terletak di Jalan Veteran No. 2, Timur alun-alun Kebumen pada tanggal 16 Oktober 2018 mewawancarai staf Dinas Kebudayaan Kabupaten Kebumen yaitu Bapak Bambang Eko Susilohadi untuk memperoleh data tentang tari Lawet di Kabupaten Kebumen. Sumber data sekunder dalam penelitian diperoleh dari Ketua Sanggar Suryo Sumirat (Bapak Eko Haryono) dan Ibu Sukini selaku istri dari pencipta tari Lawet untuk mendapatkan informasi tambahan mengenai bentuk pertunjukan tari Lawet. Masyarakat Kebumen penikmat tari Lawet sebagai informan pelengkap yang diyakini dapat memberikan tambahan informasi.

Lokasi penelitian berada di Sanggar Suryo Sumirat yang berlokasi di Desa Pesuningan, Kecamatan Prembun, Kabupaten Kebumen. Sanggar Suryo Sumirat diketuai dan didirikan oleh Bapak Eko Haryono yang juga selaku staf di Dinas Kebudayaan Kabupaten Kebumen. Teknik pengumpulan data yang peneliti gunakan ialah teknik observasi, wawancara dan teknik dokumentasi. Teknik observasi yang digunakan dalam penelitian nilai estetis tari Lawet adalah mendapatkan informasi mengenai keberadaan, bentuk serta nilai estetis tari Lawet di Kabupaten Kebumen. Wawancara merupakan komunikasi antara lebih dari satu orang untuk mendapatkan suatu informasi, dimana salah satu pihak menjadi narasumber. Pada tanggal 16 Oktober 2018 peneliti melaku wawancara dengan sumber primer dan sumber sekunder.

Peneliti menggunakan data dokumentasi untuk mengumpulkan dokumen berupa foto, video, catatan. Foto mengenai ragam gerak, rias, dan kostum tari Lawet. Dokumen berupa video tari Lawet ketika pentas. Dokumentasi menghasilkan dokumen dalam bentuk foto dan video.

Keabsahan data dalam penelitian nilai estetis tari Lawet di Kabupaten
Kebumen menggunakan teknik triangulasi sumber. Triangulasi sumber untuk menguji kredibilitas data dilakukan dengan cara mengecek data yang telah diperoleh melalui beberapa sumber (Sugiyono, 2013: 373).

Triangulasi yang digunakan dalam penelitian adalah triangulasi sumber yaitu membandingkan dan mengecek informasi yang diperoleh dalam pendokumentasi, observasi, dan wawancara mendalam tentang Nilai Estetis Tari Lawet di Kabupaten Kebumen. Data yang diperoleh melalui wawancara diupayakan berasal dari banyak narasumber, kemudian dipadukan, sehingga data yang diperoleh dapat dipertanggungjawabkan. Pengecekan data tersebut dengan mewawancarai narasumber yang mengetahui sejarah dan nilai estetis tari Lawet di Kabupaten Kebumen yaitu Dinas Pendidikan dan Kebudayaan Kabupaten Kebumen, pencipta tari, penggarap tari, ketua sanggar, dan masyarakat.

Teknik analisis data yang diperoleh dalam penelitian ini menggunakan metode analisis yaitu dengan menjelaskan secara jelas dari hasil data yang diperoleh. Analisis data ini dilakukan melalui beberapa tahap yaitu: reduksi data, penyajian data dan penarikan kesimpulan.

\section{HASIL PENELITIAN}

\section{Sejarah Tari Lawet}

Sejarah diciptakannya tari Lawet yaitu pada tahun 1975 di Kebumen sedang mempersiapkan akan mengikuti sendratari di Semarang. Kasi Kebudayaan (Sukardi) membentuk tim pelatih tari karawitan yang terdiri dari Sruwono, Rabimin, Sardjono, Sardjoko. Keempat pelatih tersebut diserahi menggarap Sendratari mengambil cerita "Jaka Sangkrip" yang telah mendarah daging di hati masyarakat Kebumen sebab ada hubungannya dengan sejarah Kebumen. Di dalam Sendratari Jaka Sangkrip tersebut terdapat adegan yang menggambarkan Jaka Sangkrip sedang bertapa di Goa Karangbolong. Keempat pelatih sepakat memberikan gerakan burung lawet yang sedang beterbangan 
untuk mendukung adegan di Karangbolong tersebut. Hal inilah yang menjadi awal mula munculnya gagasan penciptaan tari Lawet.

Sardjoko sebagai salah satu anggota tim pelatih diberi tugas untuk membuat gerakan burung Lawet. Gerak yang tersusun masih sangat sedikit karena pada saat itu gerakan yang dibutuhkan hanya sebagai pendukung/pengisi suasana. Setelah Sendratari Jaka Sangkrip di Semarang telah usai, tari Lawet pun tidak ada kelanjutannya sampai beberapa tahun. Tim pelatih kembali diberi kesempatan untuk melanjutkan penyusunan tari Lawet melalui acara penyambutan tamu di kantor Transmigrasi Kabupaten Kebumen yang bertempat di Gedung Transisto dengan menciptakan sendratari "Ngundhuh Sarang Burung Lawet". Koreografi burung lawet disini lebih dominan, sebab Lawet adalah objek utama dalam sendratari Ngundhuh Sarang Burung Lawet.

Inspirasi lambang daerah dan tugu lawet, Sardjoko telah mantap untuk mengembangkan tenaga dan pikiran agar burung lawet tidak hanya sebagai burung kebanggaan yang menghasilkan sarang burung tetapi lawet dapat dijadikan sebagai kebanggaan berupa tari yang dapat dinikmati oleh semua masyarakat Kabupaten Kebumen. Kesempatan yang baik dalam menuangkan ide membekukan gerak tari Lawet yaitu pada acara Perkemahan Saka Bhayangkara Daerah Jawa Tengah di Bumi Perkemahan Pramuka Widara, Kecamatan Sadang Kabupaten Kebumen yang pada waktu itu Kebumen menginginkan adanya tari identitas untuk ditampilkan secara masal.

$$
\text { Pada bulan Februari 1989, }
$$

Sardjoko mulai kembali menyusun gerakgerak tari Lawet. Agar lebih mantap dalam penyusunannya, Sardjoko mengadakan penelitian, pengamatan, dan mencari inspirasi ke Goa Karangbolong untuk melihat langsung kehidupan burung Lawet. Dalam penyusunan ini Sardjoko mengingat-ingat gerakan yang lama dan ditambah dengan gerak penemuan baru. Pijakan geraknya mengambil dari beberapa gaya daerah antara lain gaya Banyumasan, gaya Surakarta dan sedikit gaya Bali. Iringannya menggunakan gending lama yaitu lagu Onde-onde laras pelog patet barang. Setelah gerak dan iringan selesai, kemudian mengadakan rekaman untuk bahan penataran/latihan bersama. Tari Lawet ditularkan kepada guru/pelatih SMP Negeri di Kota Kebumen untuk diajarkan kepada siswa.

Sardjoko dibantu oleh dua orang pelatih dari seksi Kebudayaan yaitu Sri Kingkin Retno Utami dan Bambang Eko Susilohadi yaitu sebagai peraga untuk menyusun/membakukan gerak. Gending iringan diberi nama lancaran "Lawet Aneba" laras pelog patet barang. Iringan tari Lawet menggunakan laras pelog patet barang karena rasanya lebih mendukung dengan kebutuhan rasa yang prenes, riang gembira dan lincah. Susunan tari Lawet telah disempurnakan dengan iringan yang baru dibantu oleh Sukimun sebagai penata iringan. Pak sardjoko yang bisa menari dan bisa gamelan serta kendang sehingga menjadi ketua tim dan mengkolaborasi iringan dan tarian. Kemudian diadakan rekaman untuk diabadikan. Setelah iringan jadi lalu disebarkan melalui pelatihan.

Pada pertengahan bulan Maret 1991, tari Lawet disebarluaskan lewat penataran pelatih tari se-Kabupaten Kebumen yang diikat dalam GALATRI (Gabungan Pelatih Tari). Pada saat itu tari Lawet ditetapkan sebagai materi muatan lokal untuk siswa Sekolah Dasar. Akan tetapi, pada tahun 2005 peraturan tersebut dihapuskan karena terdapat permasalahan mengenai hak cipta tari Lawet. Sehingga tari Lawet tidak lagi masuk dalam muatan lokal wajib SD.

\section{Nilai Estetis Tari Lawet}

Penilaian karya seni adalah suatu kegiatan dimana bisa terdapat banyak perbedaan faham antara para ahli, para sastrawan, para budayawan malahan justru antara para seniman sendiri (Djelantik 1999:11). Semua benda atau peristiwa kesenian mengandung tiga aspek yang mendasar yakni wujud atau rupa, bobot atau isi, dan penampilan (Djaelantik 1999: 17). Pengertian konsep wujud meliputi bentuk atau unsur yang mendasar dan struktur. Isi atau bobot mempuntai tiga aspek yaitu suasana, 
gagasan, dan pesan. Penampilan kesenian memiliki tiga unsur yang berperan yaitu bakat, keterampilan, dan sarana atau media (Djelantik 1999:18).

Beranjak dari hal tersebut maka terdapat tiga aspek penilaian keindahan tari Lawet yaitu aspek bentuk, aspek bobot, dan aspek penampilan. Ketiga aspek tersebut harus saling melengkapi, dan merupakan satu kesatuan yang selaras. Nilai estetis tari Lawet tidak terlepas dari unsur wujud gerak maupun isinya. Nilai estetis pada tari Lawet juga terletak pada keseluruhan keutuhan, dan keterpaduan seluruh komponen secara harmonis.

\section{Bentuk Tari Lawet}

Nilai estetis tari Lawet dilihat dari aspek wujud yaitu dari segi bentuk pertunjukan meliputi gerak, iringan, rias, busana, pelaku, dan tempat pentas. Adapun gerak, iringan, tata rias dan busana tari Lawet sebagai berikut.

\section{Gerak Tari Lawet}

Nilai estetis gerak tari Lawet dilihat melalui elemen-elemen tubuh yang digerakan. Elemen tersebut dapat dilihat melalui aspek ruang, waktu, dan tenaga. Unsur gerak ruang yaitu volume dan levelnya, unsur gerak tenaga yaitu intensitas dan tekanan, sedangkan unsur gerak waktu yaitu tempo dan ritmenya.

Proses penciptaan gerak diawali dengan mengadakan survei ke karang bolong, ke goa tempat burung-burung lawet bersarang sekalipun tidak bisa turun langsung ke goa karena memang harus tenaga ahli. Jadi hanya melihat dan mengamati bagaimana solah tingkah karakter burung lawet itu sendiri. Diantaranya yaitu saat burung lawet keluar masuk ke goa, mencari makan, aktifitas mulai dari perkawinan, ada istilah mengerami telur, menetas, namun tidak menggambarkan bagaimana ia beranak.

Gerakan tari Lawet lincah dan ceria, disesuaikan dengan gerak burung Lawet. Sehingga gerakan dalam tari Lawet meliputi ngulet, loncat egot, angklingan, didis, lenggut, nyucuk, ukel, lincah nyucuk, dan kepetan.

Gerak Tari Lawet diawali pada suasana pagi menjelang matahari terbit.
Burung Lawet bangun dari tidurnya yang digambarkan dengan sayap kanan dan kiri dibuka lebar sampai urat terlihat kencang. Hal ini menandakan bahwa burung lawet segar bugar dan semangat dalam mencari mangsa. Gerak awal ini disebut dengan ngulet. Dengan perasaan gembira, burung lawet pergi meninggalkan sarangnya dan keluar dari mulut Goa Karangbolong. Mereka terbang dengan lincah di atas gelombang samudera laut selatan yang mengerikan itu. Kemudian burung-burung lawet itu terbang menuju hutan di sekitar Karangbolong untuk mencari mangsa. Sambil mencari mangsa, burung lawet bercanda, bersuka ria dan mencari pasangan masing-masing yang digambarkan dengan bermacam-macam gerak, seperti menyambar serangga, didis, ngasah cucuk, dan meloncat-loncat lincah yang disertai desiran ombak.

Ada 15 ragam gerak burung lawet yaitu ngulet, aburan, singgetan, angklingan, kirig, didis, loncat egot, sileman, lenggut maju serong, lincak nyucuk, ukel nyucuk, kepetan, tranjalan, ngasah cucuk, dan membuat sarang.

Gerak Tari Lawet menggunakan volume gerak yang kuat, tempo gerak yang cepat, dan penggunaan aksen gerak pada gerak kaki sehingga memberikan kesan yang lincah dan energik. Gerak tari Lawet cenderung menghasilkan gerakan yang lincah, terkadang gerakannya halus dan mengalun. Gerak lincah dan energik terlihat dalam gerakan aburan. Sedangkan gerakan yang halus dan mengalun terdapat pada gerak membuat sarang.

\section{Tata Rias Tari Lawet}

Rias yang digunakan adalah rias cantik, untuk lebih menguatkan karakter burung Lawet pada bagian mata digunakan pola jahitan seperti pada rias tari Bedhaya dan Srimpi gaya Yogyakarta. Teknik jahitan ini menunjukan bentuk mata dari seekor burung yang kecil, tipis dan cenderung tertarik ke samping dengan bentuk alis menjangan ranggah. Bentuk alis menjangan ranggah bukan merupakan bentuk khusus untuk menunjukan karakter burung. Bentuk alis menjangan ranggah bahkan biasa digunakan untuk menggambarkan karakter rusa pada tari Kidang. 
Pemilihan bentuk alis lebih ditujukan untuk memperkuat karakter binatang pada tari Lawet. Tata rias karakter burung Lawet juga menggunakan gliter pada bagian mata untuk memberikan kesan lebih berani dan glamor. Selain itu, rias wajah tari Lawet menggunakan godeg dan laler menclok.

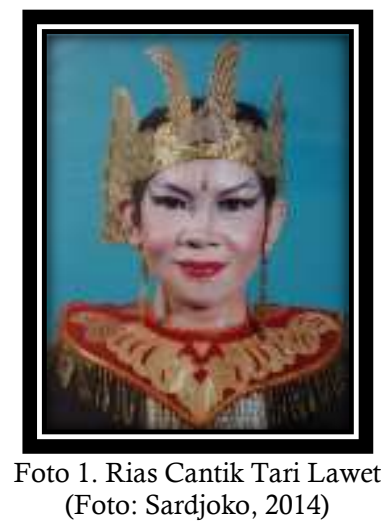

Nilai estetis tata rias pada tari Lawet yaitu terlihat pada bagian mata yang menggunakan pola jahitan kecil, tipis dan cenderung tertarik kesamping untuk menunjukan bentuk mata dari seekor burung. Selain itu keindahan tata rias tari Lawet juga terlihat dari bentuk alis menjangan ranggah yang ditujukan untuk memperkuat karakter binatang pada tari Lawet, serta penggunaan gliter pada bagian mata yang memberikan kesan lebih berani dan glamor.

\section{Tata Busana Tari Lawet}

Pada awalnya, kostum tari Lawet sangat sederhana yang hanya menyesuaikan dengan warna dasar burung lawet dan belum memakai kelengkapan lainnya. Supaya terlihat menarik, penata tari merancang kostum tari Lawet dengan dibantu oleh penjahit atau persewaan pakaian tari Karya Busana Kebumen. Warna dasar yang diambil untuk kostum tari Lawet adalah hitam dan putih. Warna lain yaitu biru, untuk menggambarkan suasana air laut. Berikut adalah busana yang dipakai dalam pementasan tari Lawet : Jamang, Garuda Mungkur berbentuk burung lawet berwarna kuning emas, Baju atau kaos hitam yang berserat putih pada bagian depan, celana hitam, sayap warna hitam bergambar bulu, kalung kace berwarna dasar merah dengan hiasan kuning emas, sonder berwarna putih dengan garis tepi berwarna biru, rampek berwarna biru.

Nilai estetis yang terdapat pada kostum penari Lawet adalah penggunaan warna. Sebagian besar kostum tari Lawet terdiri dari warna merah, emas, biru, putih, dan hitam. Warna hitam menggambarkan bulu dari burung lawet. Warna merah memberi kesan berani yaitu keberanian burung lawet dalam mengarungi samudra serta keberanian manusia dalam berjuang mendapatkan sarang burung lawet dengan nyawa sebagai taruhannya. Warna biru menggambarkan alam lingkungan sekitar burung lawet yaitu awan dan samudra. Warna putih malambangkan kesucian dari burung lawet. Sedangkan warna emas menggambarkan kemahalan dari harga burung dan sarang lawet itu sendiri.

Tata rias dan busana dalam penampilan tari sangat erat hubungannya untuk mendukung penampilan tari. Dengan menggunakan tata rias dan busana penampilan tari Lawet akan lebih menarik. Penggunaan sayap juga akan menonjolkan karakter yang dibawakan oleh penari.

Iringan

Iringan dalam tari Lawet menggunakan Gendhing "Lancaran Lawet Aneba" dengan Laras Pelog Pathet Barang. Gending iringan tari Lawet diciptakan sesuai dengan gerak tarian yang memiliki suasana gembira, senang dan lincah. Penciptaan gending tarian ini dilatarbelakangi oleh suasana di Karangbolong. Misalnya, suara desiran ombak yang bergemuruh, suasana di dalam goa Karangbolong yang konon ceritanya menakutkan dan juga kehidupan burung lawet. Syairnya sebagai berikut :

"bangbang wetan pratandha wus gagat enjang. Sesamberan arebut margo mbarubul saking guwa Karang bolong peksi lawet ireng menges wulune cukat trengginas katon gembira aneng luhuring samudro gung ngupa boga tumekaning surup surya andalidir pra lawet bali mring guwa". 
Yang memiliki arti "langit di ufuk timur sudah terlihat memerah tandanya mulai pagi. Saling terbang berebut jalan keluar. Dari gua Karangbolong burung lawet yang hitam pekat bulunya, cekatan dan trengginas, terlihat gembira, berada di atas samudra luas. Mencari makan sampai matahari tenggelam, bersamaan/ beriringan burung lawet pulang ke gua".

Maksud dari syair pengiring tari Lawet sangat berhubungan erat dengan kehidupan manusia dalam kehidupan sehari-hari. Ketika waktu sudah menunjukkan pagi hari, manusia harus segera bergegas bangun dari tidurnya dan mempersiapkan segala aktivitas yang akan dilaksanakan. Manusia harus semangat dalam mencari ilmu bagi para pelajar dan mencari rezeki untuk memenuhi kebutuhan hidup. Manusia dilarang bermalas-malasan, harus giat dalam melakukan segala hal. Tanpa pamrih saling bekerja sama dan bersaing dengan orang lain untuk mencapai suatu hal yang ingin diraih. Ketika waktu sudah menunjukkan sore hari, manusia juga harus segera bergegas pulang dan kembali ke rumah masing-masing. Selain untuk beristirahat, manusia juga membutuhkan kehangatan untuk berkumpul kembali bersama keluarga dan orang terdekat. Hal tersebut mengajarkan manusia untuk melakukan sesuatu dengan tepat waktu, usaha, kerja keras, dan saling bekerja sama dengan yang lain.

Pengolahan iringan secara optimal dapat diwujudkan apabila pengrawit maupun penari memiliki bakat dan ketrampilan untuk mengolah karya tersebut. Apabila penari tidak memiliki bakat dan ketrampilan maka akan sulit untuk mengikuti irama musik. Kebanyakan penari lawet awalnya tidak bisa menari, namun mereka giat berlatih sehingga sampai saat ini mereka bisa menari dan dipentaskan. Aspek irama sangat berhubungan erat dengan bakat dan ketrampilan melalui pengrawit dan penari yang mewujudkannya.

\section{Tempat Pentas}

Suatu pertunjukan apapun bentuknya selalu memerlukan tempat atau ruangan guna menyelenggarakan pertunjukan itu sendiri. Sebuah pertunjukan dapat dipentaskan pada tempat terbuka dan tempat tertutup.

Tempat pentas tari Lawet bisa dipanggung, maupun di lapangan untuk tari masal. Tari Lawet bisa dipentaskan di panggung maupun tempat terbuka, seperti lapangan, halaman rumah. Hal ini karena tari Lawet bisa dipentaskan secara masal, tunggal, maupun berpasangan.

\section{Pelaku}

Suatu pertunjukan membutuhkan pelaku seni atau orang yang terlibat didalamnya. Kekompakan setiap individu sangat berpengaruh pada pementasan. Tanpa adanya pelaku seni tari Lawet tidak dapat berjalan. Jenis kelamin penari dalam tari Lawet semuanya perempuan yaitu usia anak-anak maupun remaja.

\section{Bobot / Isi}

Berbicara tentang bobot pada tari Lawet tidak terlepas dari isi tari tersebut, yang di dalamnya terdiri dari suasana, ide, dan pesan. Berikut adalah penjelasan mengenai suasana, ide, dan pesan.

Suasana pada tari Lawet terwujud dari iringannya yang mendukung suasana, bunyi kendang dan balungan yang keras memperkuat suasana gembira dan karakter lincah.

Ide tari Lawet muncul ketika Kabupaten Kebumen menginginkan adanya tari identitas. Kemudian dipilihlah tari Lawet sebagai tari identitas Kebumen karena pada saat itu Kabupaten Kebumen penghasil devisa negara atau pemerintah yang terbesar adalah dari sarang burung lawet. Burung Lawet merupakan simbol logo Kabupaten Kebumen, sehingga Bapak Sardjoko dibantu beberapa seniman Kebumen lainnya semakin mantap memilih tari Lawet sebagai tarian identitas Kebumen.

Pesan yang disampaikan umumnya tidak secara langsung tetapi lewat ungkapan-ungkapan simbolik. Tari Lawet memiliki dua pesan yang ada didalamnya yaitu pesan moral dan pesan ekspresif. Pesan moral yang disampaikan pada tari Lawet agar manusia tetap ingat kepada Tuhan yang menciptakan alam semesta. Sebagai manusia diharapkan memiliki sifat yang baik, tidak menyombongkan diri. Pesan ekspresif muncul ketika penari 
sedang menari, pesan ini memiliki arti adanya penyampaian pesan tentang isi tarian tersebut, misalnya pada gerak ngulet merupakan gerakan yang menggambarkan burung lawet ketika bangun dari tidurnya. Secara umum, manusia selalu melakukan gerakan ini ketika bangun tidur dan setelah beraktivitas. Gerak ini bermaksud melemaskan otot-otot sehingga tubuh merasa segar bugar kembali. Hal tersebut berhubungan erat dengan kesehatan manusia supaya rajin berolahraga dan menjaga kesehatan jasmani.

\section{Penampilan}

Berbicara tentang penampilan pada tari Lawet terdiri dari bakat, ketrampilan, dan sarana. Berikut adalah penjelasan mengenai bakat, ketrampilan, dan sarana.

Bakat yang harus dikuasai oleh setiap penari Lawet adalah bisa menari dengan gerakan yang luwes. Bakat yang harus dikuasai oleh pengrawit yaitu dapat menabuh gamelan sesuai notasi iringan tari Lawet.

Teknik keterampilan yang harus dimiliki setiap pemainnya yaitu mampu menari sesuai dengan gerakan dan mampu menyesuaikan iringan dan gerakan. Setiap orang memiliki ketrampilan yang berbeda-beda, sehingga dibutuhkan latihan rutin untuk menjadikan setiap pemainnya lebih trampil.

Nilai keindahan pelaku terlihat pada kekompakan dalam menari sebuah tarian. Dengan gerak yang sama lincah dan kompak akan menimbulkan kesan indah ketika dilihat. Setiap individu saling mengisi dan menutupi kekurangan. Gerak-gerak yang memiliki arti akan tersampaikan kepada penonton. Pelaku yang masih berusia anak-anak maupun remaja memberikan kesan gadis muda cantik yang lincah dan ceria.

Sarana pada tari Lawet yaitu seluruh aspek penunjang pementasan seperti busana, tata rias. Dengan adanya busana, tata rias maka penampilan tari Lawet ketika pentas akan lebih menarik perhatian penonton.

\section{SIMPULAN}

Tari Lawet merupakan tari identitas kabupaten Kebumen mempunyai nilai estetis yang terlihat dari aspek bentuk, bobot/isi, dan penampilan. Aspek bentuk meliputi gerak, tata rias dan tata busana, iringan, tempat pentas dan pelaku. Aspek isi meliputi tema, ide atau gagasan dan pesan tari. Aspek penampilan meliput bakat, ketrampilan, dan sarana.

Nilai estetis tari Lawet dari segi bentuk pertunjukannya nampak pada gerak yang dilakukan penari Lawet saat gerakan aburan mengikuti alunan iringan musik menimbulkan kesan indah dan lincah. Gerak yang dilakukan penari Lawet cenderung berlevel sedang. Ragam gerak yang terdapat dalam pertunjukkan tari Lawet menimbulkan kesan dinamis dan lincah. Penggunaan warna pada kostum tari Lawet memiliki makna tersendiri. Tempat pertunjukkan tari Lawet bisa di area terbuka maupun tertutup.

Isi pertunjukan tari Lawet nampak pada gagasan, suasana, dan pesan yang ada dalam pertunjukan tari Lawet. Ide tari Lawet muncul ketika Kabupaten Kebumen menginginkan adanya tari identitas. Pesan yang disampaikan umumnya tidak secara langsung tetapi lewat ungkapan-ungkapan simbolik. Tari Lawet memiliki dua pesan yang ada didalamnya yaitu pesan moral dan pesan ekspresif.

Penampilan tari Lawet nampak pada bakat, ketrampilan dan sarana. Bakat yang harus dikuasai oleh setiap penari Lawet adalah bisa menari dengan gerakan yang luwes. Setiap orang memiliki ketrampilan yang berbeda-beda, sehingga dibutuhkan latihan rutin untuk menjadikan setiap pemainnya lebih trampil. Sarana pada tari Lawet yaitu seluruh aspek penunjang pementasan seperti busana, tata rias, tempat pertunjukan.

Saran peneliti untuk seniman, diharapkan tetap mempertahankan nilainilai yang terkandung dalam tari Lawet karena berkaitan dengan estetis atau keindahan penyajian tari Lawet. Bagi masyarakat, hendaknya mencintai budaya sendiri yaitu tari Lawet yang sudah diangkat sebagai tari identitas kabupaten 
Kebumen. Bagi pemerintah Kabupaten Kebumen, agar tari Lawet lebih dikenal sebaiknya sering mengadakan festival atau lomba tari Lawet dan lebih digiatkan lagi sebagai materi ajar di sekolah.

\section{DAFTAR PUSTAKA}

Djelantik. (1999). Estetika. Bandung: Masyarakat Seni Pertunjukan Indonesia.

Jazuli, Muhammad. (2016). Peta Dunia Seni Tari. Sukoharjo: CV. Farishma Indonesia.

Lutfyana, E. (2015). Eksistensi Tari Lawet di Kabupaten Kebumen. Skripsi Studi Pendidikan Seni Tari Universitas Negeri Yogyakarta.

Sardjoko. 1996. Sekilas tentang Tari Lawet. Kebumen : Depdikbudcam Alian

Setyawati, A. (2017). Nilai Estetis Kesenian Dangsak Di Desa Watulawang Kecamatan Pejagoan Kabupaten Kebumen. Skripsi Studi Pendidikan Seni Tari Universitas Negeri Semarang.

Sugiyono. 2013. Metode Penelitian Pendidikan. Bandung: Alfabet. 